\title{
The Effect of Regular Physical Activity on the Left Ventricle Systolic Function in Patients With Chronic Coronary Artery Disease
}

\author{
R. PANOVSKÝ ${ }^{1}$, P. KUKLA ${ }^{1}$, R. JANČÁR ${ }^{1}$, J. MELUZÍN ${ }^{1}$, J. JANČÍK ${ }^{2}$, V. KINCL ${ }^{1}$, \\ K. POLOKOVÁ ${ }^{1}$, L. MÍFKOVÁ ${ }^{2}$, A. HAVELKOVÁ ${ }^{2}$, R. LÁTALOVÁ ${ }^{2}$, P. DOBŠ́́ ${ }^{2}$, \\ M. PEŠL ${ }^{1}$
}

${ }^{1}$ First Department of Internal Medicine/Cardioangiology, International Clinical Research CenterICRC, St. Anne's Hospital, Masaryk University, Brno, Czech Republic, ${ }^{2}$ Department of Functional Diagnostic and Rehabilitation, St. Anne's Hospital, Masaryk University, Brno, Czech Republic

Received February 15, 2011

Accepted August 3, 2011

On-line October 12, 2011

\section{Summary}

The purpose of this study was to assess the influence of aerobic training on the left ventricular (LV) systolic function. Thirty patients with stable coronary artery disease, who had participated in the conducted 3-month physical training, were retrospectively divided into 2 cohorts. While patients in the cohort I $(n=14)$ had continued training individually for 12 months, patients in the cohort II $(n=16)$ had stopped training after finishing the conducted program. Rest and stress dobutamine/atropine echocardiography was performed in all patients before the training program and 1 year later. The peak systolic velocities of mitral annulus (Sa) were assessed by tissue Doppler imaging for individual LV walls. In addition, to determine global LV systolic longitudinal function, the four-site mean systolic velocity was calculated (Sa glob). According to the blood supply, left ventricular walls were divided into 5 groups: A- walls supplied by nonstenotic artery; B- walls supplied by coronary artery with stenosis $\leq 50 \%$; C- walls supplied by coronary artery with stenosis 51-70 \%; D- walls with stenosis of supplying artery 71-99 \%; and E- walls with totally occluded supplying artery. In global systolic function, the follow-up values of Sa glob in cohort I were improved by $0.23 \pm 0.36$ as compared with baseline values at rest, and by $1.26 \pm 0.65 \mathrm{~cm} / \mathrm{s}$ at the maximal load, while the values of Sa glob in cohort II were diminished by $0.53 \pm 0.22$ $(p=N S)$, and by $1.25 \pm 0.45 \mathrm{~cm} / \mathrm{s} \quad(p<0.05)$, respectively. Concerning the resting regional function, the only significant difference between cohorts in follow-up changes was found in walls $E$ : $0.37 \pm 0.60$ versus $-1.76 \pm 0.40 \mathrm{~cm} / \mathrm{s}(p<0.05)$. At the maximal load, the significant difference was found only in walls $A$ $(0.16 \pm 0.84$ versus $-2.67 \pm 0.87 \mathrm{~cm} / \mathrm{s} ; \mathrm{p}<0.05)$. Patients with regular 12-month physical activity improved their global left ventricle systolic function mainly due to improvement of contractility in walls supplied by a totally occluded coronary artery.

\section{Key words}

Coronary artery disease • Aerobic training • Left ventricle systolic function

\section{Corresponding author}

R. Panovský, First Department of Internal Medicine/ Cardioangiology, International Clinical Research Center - ICRC, St. Anne's Hospital, Masaryk University, Pekařská 53, 65691 Brno, Czech Republic. Fax: +420 543182205. E-mail: panovsky@fnusa.cz

\section{Introduction}

Beneficial effects of cardiac rehabilitation (CR) on secondary prevention of patients with coronary artery disease are now well-established. The major objective benefits are an increased exercise capacity (Hambrecht $e t$ al. 2000) and reduced rates of cardiac events and mortality (Oldridge et al. 1988, Hadkell et al. 1994). In addition, beneficial effects on coronary risk factors blood pressure, lipid levels, glucose metabolism, body weight, as well as on the endothelial function and psychological well-being were proved (Shephard and Balady 1999).

On the other hand, only limited data exists 
concerning the effect of $\mathrm{CR}$ on left ventricular (LV) function. Some authors suggest improvements in cardiac function (Belardinelli et al. 1996, Giannuzzi et al. 1997, Hambrecht et al. 2000, Klecha et al. 2007), whereas others have not found any significant differences between exercise training groups and controls (Dubach et al. 1997, Giannuzzi et al. 2003). The different results may be due to differences in intensity and duration of training, measurement techniques or patient populations. However, in majority of the studies, LV function has been evaluated by $\mathrm{LV}$ ejection fraction (EF) measurements. It is well known that LVEF quantification using standard twodimensional (2D) echocardiography is strongly dependent on image quality and endocardial border delineation.

Tissue Doppler imaging (TDI) is an echocardiographic technique employing the Doppler principle to measure the velocity of myocardium. PulsedTDI permits quantification of regional longitudinal myocardial velocities with high temporal resolution and is feasible even in poor acoustic windows. Hence, TDI offered a potentially more accurate quantitative assessment of both regional and global LV function including even more minor changes in systolic LV function that are not detectable during 2D echocardiographic evaluation of LVEF.

The purpose of this study was to assess the influence of aerobic training on the LV systolic function using TDI measurements.

\section{Methods}

\section{Patient population and study protocol}

The study comprised 30 patients with stable coronary artery disease (proved by the coronary angiography performed before the study). All of them had participated in the conducted 3-month physical CR training. The continuation of physical training was recommended to all patients. After 1 year period, these patients were retrospectively divided into 2 cohorts. While patients in the cohort I $(n=14)$ had continued training individually for 12 months, patients in the cohort II $(n=16)$ had stopped training after finishing the conducted CR program.

Rest and stress dobutamine/atropine echocardiography was performed in all patients before the training program and 1 year later. For the evaluation of regional systolic LV function, the pulsed TDI was used.

According to the blood supply, LV walls were divided into 5 groups: A- walls supplied by nonstenotic artery; B- walls supplied by coronary artery with stenosis $\leq 50 \%$; C- walls supplied by artery with stenosis 51-70 \%; D- walls with stenosis of supplying coronary artery 71-99 \%; and E- walls with totally occluded supplying artery.

The study was in accordance with the Declaration of Helsinki (2000) of the World Medical Association, was approved by the institutional ethics committee and written consent was obtained from each patient.

\section{Physical training}

All patients had participated in the conducted outpatient CR. The program offered 3 months of 3 times per week sessions. Each session lasted for 60 minutes and consisted of 3 different phases: 10 minutes warm-up, period of aerobic exercise on bicycle ergometer with load intensity at the level of anaerobic threshold $(20 \mathrm{~min})$, period of resistance training performed on combined training machine $(20 \mathrm{~min})$, and relaxation period $(10 \mathrm{~min})$. Aerobic exercise intensity was individually prescribed according to symptom-limited spiroergometry (Blood Gas Analyser, MedGraphics, USA) that was provided before training period for the evaluation of anaerobic threshold.

The 9-months individual training of cohort I consisted of regular physical activity performed for a minimum of one hour at least three times a week. As a regular physical activity the patients have been asked to choose either cycling, riding a velo-ergometer or swimming.

\section{Echocardiography}

Using commercially available equipment Philips Sonos 5500 (Andover, USA) with a $2.5 \mathrm{MHz}$ transducer, echocardiographic examinations were performed in one centre by one experienced echocardiographer. 2D images of standard views and pulsed TDI of apical 4- and 2-chamber views were acquired and recorded on videotape for off-line analyses. The peak systolic velocities of myocardium adjacent to the mitral annulus (Sa) were assessed by TDI for individual LV walls: septum, lateral, anterior, and inferior walls. In addition, to determine global LV systolic longitudinal function, the four-site mean systolic velocity was calculated (Sa glob). Velocities were evaluated at rest and at the maximal load.

Dobutamine echocardiography was performed in all patients. Dobutamine was infused with mechanical 
pump, starting at a dose of $5 \mu \mathrm{g} / \mathrm{kg} / \mathrm{min}$. At 3-minute intervals, the dose was increased incrementally to 10,20 , $30,40 \mu \mathrm{g} / \mathrm{kg} / \mathrm{min}$ until a maximal dose was reached or target heart rate was attained. Intravenous atropine was given in one bolus dose of $0.5 \mathrm{mg}$ if the target heart rate was not reached. After the test has been terminated, patients were monitored until baseline condition returned.

\section{Statistical analysis}

The changes of global and regional systolic function of individual LV wall groups were compared between cohorts at rest and at the maximal load. To assess normal distribution of variables, the KolmogorovSmirnov test was used. An unpaired t-test and Mann-
Whitney $U$ test were applied to compare the values of parameters between cohorts; $\mathrm{p}<0.05$ was considered statistically significant.

\section{Results}

Baseline characteristics and coronary angiography findings of patients are shown at Table 1 and 2. The majority of parameters have been similar in the two groups - just differences between the number of men and women and the difference between patients age in both cohorts have been found. No serious adverse events were found in either group during the follow-up.

Table 1. Characteristics of the study population.

\begin{tabular}{|c|c|c|c|c|}
\hline \multirow{2}{*}{$\begin{array}{l}\text { Parameter } \\
\text { Age (years) }\end{array}$} & \multicolumn{2}{|c|}{ Cohort I $(n=14)$} & \multicolumn{2}{|c|}{ Cohort II $(n=16)$} \\
\hline & 60 & $(10)$ & $69 *$ & $(8)$ \\
\hline Men & 13 & $(93 \%)$ & $8^{*}$ & $(50 \%)$ \\
\hline Diabetes mellitus & 4 & $(29 \%)$ & 5 & $(31 \%)$ \\
\hline Hypertension & 14 & $(100 \%)$ & 16 & $(100 \%)$ \\
\hline Hyperlipidemia & 14 & $(100 \%)$ & 15 & $(94 \%)$ \\
\hline Previous myocardial infarction & 10 & $(71 \%)$ & 9 & $(57 \%)$ \\
\hline$L V E F(\%)$ & 50.4 & $(2.9)$ & 47.9 & $(2.7)$ \\
\hline No of stenotic arteries $(\geq 70 \%)$ & 2.1 & $(0.2)$ & 1.6 & $(0.2)$ \\
\hline \multicolumn{5}{|l|}{ Medication } \\
\hline Aspirin & 14 & $(100 \%)$ & 15 & $(94 \%)$ \\
\hline Beta blocker & 14 & $(100 \%)$ & 16 & $(100 \%)$ \\
\hline ACE inhibitor & 10 & $(71 \%)$ & 11 & $(70 \%)$ \\
\hline Statin & 13 & $(93 \%)$ & 16 & $(100 \%)$ \\
\hline Diuretics & 4 & $(29 \%)$ & 5 & $(31 \%)$ \\
\hline Nitrates & 8 & $(57 \%)$ & 11 & $(69 \%)$ \\
\hline
\end{tabular}

The values are expressed as the mean supplied by standard error (in parentheses) or number (\%) of subjects. $\mathrm{LV}=$ left ventricle; $\mathrm{EF}=$ ejection fraction; No = number; ACE $=$ angiotensin-converting enzyme; $* 0<0.05$ between cohorts.

Table 2. Coronary angiography finding in cohorts.

\begin{tabular}{|c|c|c|c|c|c|c|}
\hline \multirow[t]{2}{*}{ Cohort } & \multicolumn{3}{|c|}{$I(n=14)$} & \multicolumn{3}{|c|}{ II $(n=16)$} \\
\hline & LAD & LCX & RCA & LAD & LCX & RCA \\
\hline no stenosis & $3(21 \%)$ & $2(14 \%)$ & $3(21 \%)$ & $3(19 \%)$ & $6(38 \%)$ & $5(31 \%)$ \\
\hline stenosis $\leq 50$ & $4(29 \%)$ & $7(50 \%)$ & $0(0 \%)$ & $2(13 \%)$ & $4(25 \%)$ & $4(25 \%)$ \\
\hline stenosis $51-70 \%$ & $2(14 \%)$ & $2(14 \%)$ & $3(21 \%)$ & $1(6 \%)$ & $1(6 \%)$ & $2(13 \%)$ \\
\hline stenosis $71-99 \%$ & $3(21 \%)$ & $1(7 \%)$ & $3(21 \%)$ & $4(25 \%)$ & $3(19 \%)$ & $2(13 \%)$ \\
\hline totally occluded & $2(14 \%)$ & $2(14 \%)$ & $5(36 \%)$ & $6(38 \%)$ & $2(13 \%)$ & $3(19 \%)$ \\
\hline
\end{tabular}

The values are expressed as number of arteries (\%). LAD = left anterior descending artery; LCX = left circumflex; RCA = right coronary artery. 
Table 3. Changes of Sa value after follow-up in different groups of LV walls at rest and at the maximal load.

\begin{tabular}{lcccc}
\hline Cohort & \multicolumn{2}{c}{ At rest } & \multicolumn{2}{c}{$\begin{array}{c}\text { At the maximal load } \\
\text { II (n= 16) }\end{array}$} \\
\hline Wall group & & II $(\mathbf{n}=\mathbf{1 6})$ & I (n= 14) & $-2.67 \pm 0.87 *$ \\
$A$ & $-1.56 \pm 0.93$ & $-0.86 \pm 0.38$ & $0.16 \pm 0.84$ & $0.56 \pm 1.05$ \\
$B$ & $1.29 \pm 0.63$ & $0.62 \pm 0.58$ & $3.83 \pm 1.13$ & $-0.58+1.92$ \\
$C$ & $-0.64 \pm 0.69$ & $0.14 \pm 0.88$ & $-0.42 \pm 1.02$ & $-2.29 \pm 0.86$ \\
$D$ & $-0.09 \pm 0.86$ & $-0.10 \pm 0.30$ & $-2.82 \pm 1.19$ & $0.02 \pm 0.78$ \\
$E$ & $0.37 \pm 0.60$ & $-1.76 \pm 0.40 *$ & $1.70 \pm 1.43$ & $-1.25 \pm 0.45 *$ \\
\hline
\end{tabular}

The values are expressed as the mean supplied by standard error (in parentheses). Sa = peak systolic velocity of mitral annulus; LV = left ventricle. Wall groups: A- walls supplied by nonstenotic artery; B- walls supplied by artery with coronary stenosis $\leq 50 \%$; C- walls supplied by artery with stenosis 51-70 \%; D- walls with stenosis of supplying artery 71-99 \%; and E- walls with totally occluded supplying artery. $* \mathrm{p}<0.05$ between cohorts.

The changes of Sa value after follow-up in different groups of LV walls are shown in Table 3. In global systolic function, the values of Sa glob in cohort I were improved by $0.23 \pm 0.36$ as compared with baseline values at rest, and by $1.26 \pm 0.65 \mathrm{~cm} / \mathrm{s}$ at the maximal load, while the values of $\mathrm{Sa}$ glob in cohort II were diminished by $0.53 \pm 0.22(\mathrm{p}=\mathrm{NS})$, and by $1.25 \pm 0.45 \mathrm{~cm} / \mathrm{s}$ $(\mathrm{p}<0.05)$, respectively.

Concerning the resting regional function, the only significant difference between cohorts in follow-up changes was found in walls $\mathrm{E}$ : $0.37 \pm 0.60$ versus $-1.76 \pm 0.40 \mathrm{~cm} / \mathrm{s} \quad(\mathrm{p}<0.05)$. At the maximal load, the significant difference was found only in walls $\mathrm{A}$ $(0.16 \pm 0.84$ versus $-2.67 \pm 0.87 \mathrm{~cm} / \mathrm{s} ; \mathrm{p}<0.05)$. Sa changes in other walls was not significant.

\section{Discussion}

\section{Effect of CR on global LV systolic function}

The present investigation suggests that long-term exercise training can improve LV systolic function in patients with coronary artery disease. Previous works have shown variable results in relation to influence of $\mathrm{CR}$ on the LV function (Belardinelli et al. 1996, Hambrecht et al. 2000, Giannuzzi et al. 2003, Klecha et al. 2007). The failure to assess changes in LVEF in some studies may have several reasons. It may be the result of different study populations, kind and intensity of the training programs or the measurement techniques (Webb-Peploe et al. 2000). Only patients with chronic heart failure or after myocardial infarction with moderate-to-severe LV dysfunction were included in the majority of studies assessing the influence of $\mathrm{CR}$ on $\mathrm{LV}$ function. In comparison with them, our patients had only slight depression of LVEF and not all of them underwent clinical myocardial infarction.

The intensity and duration of CR necessary for LV function improvement have not yet been sufficiently evaluated. In the analysis in the work of Piepoli (2004) the data suggested that only long-term duration over 28 weeks of $\mathrm{CR}$ may be required to reach benefits in mortality and adverse events rates. The antiremodelling effect of training with a trend towards improvement of LV functional parameters was found after 6-month training in the work of Klecha et al. (2007). On the other hand, the work of Hambrecht (2000) demonstrated that an intense $\mathrm{CR}$ program can improve resting $\mathrm{LVEF}$ in 2 weeks. In our work, just 1-year CR improved LV systolic function, while the 3-month training did not provide the sustained long-term functional improvement.

The utilization of LVEF, as an evaluated parameter of LV function, could be one of the main factor contributing to the failure of some previous studies to shown the effect of CR. LVEF is a load-dependent parameter and is very rough to assess expected slight changes of LV function. EF evaluated by 2D echocardiography is strongly dependent on image quality and endocardial border delineation. In contrast, TDI is robust, reproducible and may be more sensitive marker of LV longitudinal systolic function and it is feasible even in poor echocardiographic windows. Hence, TDI allows evaluation of even minor changes in LV function that are not detectable by $2 \mathrm{D}$ assessment. In several published data, TDI has been applied to stress echocardiography in order to overcome the limitation of only visual analysis (Cain et al. 2001, Fathi et al. 2001, Garcia et al. 2006, 
Bougault et al. 2008, Duzenli et al. 2008).

\section{Effect of $C R$ on regional $L V$ systolic function}

This present study is the first trial to evaluate the effect of $\mathrm{CR}$ on regional LV systolic function in relation to blood supply of individual LV walls. TDI was chosen for this purpose, because it permits quantification of regional longitudinal myocardial systolic velocities with a high temporal resolution and can overcome the limitation in the subjective echocardiographic evaluation of regional ventricular function (Reuss et al. 2005). Our data showed that the effect of CR on LV systolic function is caused mainly through the improvement of contractility in walls supplied by a totally occluded coronary artery. The effect of physical training and LV global and regional function was assessed by TDI also in the study of Deljanin-Ilic et al. (2007). After 6 months, LV EF increased significantly as well as the regional systolic myocardial function at the previously infarcted wall only in the training group.

Mechanisms of this training effect have not yet been established. The most likely explanation is the combination of beneficial changes in ventricular wall tension and favorable adaptation in the coronary circulation. The physical training may have beneficial effect on changes in autonomic balance toward a vagal predominance, which could limit the deleterious effects of sympathetic hyperactivity on the LV remodeling and function, analogously to treatment with beta blockers.

In patients with stable coronary artery disease, augmented delivery of blood to ischemic myocardium has been shown to take place in response to physical training (Hambrecht 2004). The beneficial effect of CR on morbidity and mortality has been attributed to the growth of collateral vessels between healthy and under-perfused myocardial regions (Shephard and Balady 1999). This theory was documented for example by work of Zbinden et al. (2007) where beneficial dose-response effect of 3-month endurance exercise training on collaterals has been found. However, other human studies have failed to document consistently the formation of collaterals. The main reason for different results may have been the lack of sensitivity of angiography to detect small coronary collaterals. The collateral growth and other coronary vascular changes may improve function of chronically hypoperfused myocardium.

Furthermore, CR has been shown to favourably affect blood flow rheology, thereby possible improving of myocardial perfusion. The improvement in myocardial blood flow to the infarcted area may lead to recovery of both global and regional LV function (Schuler et al. 1992). Although our study cannot elucidate the possible mechanism of regional functional improvement, we speculate, that combination of autonomic system changes and especially the development of collaterals may have facilitated partial functional recovery of dysfunctional but viable myocardial regions supplied by a totally occluded coronary artery.

\section{Study limitations}

Our study had several limitations. The study was retrospective, not randomized. The interpretations of results could be limited by a relatively small sample size in both cohorts. Also our study can be influenced by the difference between the number of men and women and the difference between patients age in both cohorts, because age and gender are determining factors for training effects - smaller improvements of women as well as a negative relation between age and improvement in exercise performance is known (Vanhees et al. 2004).

Another limitation is the fact, that the 9-months training of cohort II have been performed as an outpatient individual training without any supervision. The information about frequency and intensity has been obtained only from patient's anamnesis during their regular visits in outpatient department. However, very different types of training programmes are described in literature and in some studies, a home-based CR had no significant differences in the main outcomes compared with the centre-based programme (Jolly et al. 2009) or an outpatient CR led to further improvement of followed parameters in comparison to supervised CR in a hospital (Benzer et al. 2007).

Certainly, further research is required, especially in order to optimize the effectiveness of CR programs and to better understand the mechanisms responsible for the improvements related to $\mathrm{CR}$ training.

\section{Conclusion}

In our study, patients with regular 12-month physical activity improved their global left ventricle systolic function mainly due to improvement of contractility in walls supplied by a totally occluded coronary artery.

\section{Conflict of Interest}

There is no conflict of interest. 


\section{Acknowledgements}

The work was supported by European Regional Development Fund - Project FNUSA-ICRC (No. CZ.1.05/1.1.00/02.0123), by a grant of the Ministry of
Education of the Czech Republic (No. MSM 0021622402), and by a grant of Ministry of Health of the Czech Republic (IGA, No. NS/10096-4).

\section{References}

BELARDINELLI R, GEORGIOU D, CIANCI G, PURCARO A: Effects of exercise training on left ventricular filling at rest and during exercise in patients with ischemic cardiomyopathy and severe left ventricular systolic dysfunction. Am Heart J 132: 61-70, 1996.

BENZER W, PLATTER M, OLDRIDGE NB, SCHWANN H, MACHREICH K, KULLICH W, MAYR K, PHILIPPI A, GASSNER A, DÖRLER J, HÖFER S: Short-term patient-reported outcomes after different exercise-based cardiac rehabilitation programmes. Eur J Cardiovasc Prev Rehabil 14: 441-447, 2007.

BOUGAULT V, NOTTIN S, DOUCENDE G, OBERT P: Tissue Doppler imaging reproducibility during exercise. Int $J$ Sports Med 29: 395-400, 2008.

CAIN P, MARWICK TH, CASE C, BAGLIN T, DART J, SHORT L, OLSTAD B: Assessment of regional long-axis function during dobutamine echocardiography. Clin Sci 100: 423-432, 2001.

DELJANIN-ILIC M, ILIC S, STOICKOV V: Effects of continuous physical training on exercise tolerance and left ventricular myocardial function in patients with heart failure. Srp Arh Celok Lek 135: 516-520, 2007.

DUBACH P, MYERS J, DZIEKAN G, GOEBBELS U, REINHART W, VOGT P, RATTI R, MULLER P, MIETTUNEN R, BUSER P: Effect of exercise training on myocardial remodeling in patients with reduced left ventricular function after myocardial infarction. Circulation 95: 2060-2067, 1997.

DUZENLI MA, OZDEMIR K, AYGUL N, ALTUNKESER BB, ZENGIN K, SIZER M: Relationship between systolic myocardial velocity obtained by tissue doppler imaging and left ventricular ejection fraction: Systolic myocardial velocity predicts the degree of left ventricular dysfunction in heart failure. Echocardiography $\mathbf{2 5}$ : 856-863, 2008.

FATHI R, CAIN P, NAKATANI S, YU HC, MARWICK TH: Effect of tissue Doppler on the accuracy of novice and expert interpreters of dobutamine echocardiography. Am J Cardiol 88: 400-405, 2001.

GARCIA EH, PERNA ER, FARIAS EF, OBREGON RO, MACIN SM, PARRAS JI, AGUERO MA, MORATORIO DA, PITZUS AE, TASSANO EA, RODRIGUEZ L: Reduced systolic performance by tissue Doppler in patients with preserved and abnormal ejection fraction: New insights in chronic heart failure. Int J Cardiol 108: 181-188, 2006.

GIANNUZZI P, TEMPORELLI PL, CORRA U, GATTONE M, GIORDANO A, TAVAZZI L: Attenuation of unfavourable remodeling by exercise training in postinfarction patients with left ventricular dysfunction (ELVD) trial. Circulation 96: 1790-1797, 1997.

GIANNUZZI P, TEMPORELLI PL, CORRA U, TAVAZZI L: Antiremodeling effect of long-term exercise training in patients with stable chronic heart failure. Results of the Exercise in Left Ventricular Dysfunction and Chronic Heart Failure (ELVD-CHF) Trial. Circulation 108: 554-559, 2003.

HAMBRECHT R, GIELEN S, LINKE A, FIEHN E, YU J, WALTHER C, SCHOENE N, SCHULER G: Effects of exercise training on the left ventricular function and peripheral resistance in patients with chronic heart failure. A randomized trial. JAMA 283: 3095-3101, 2000.

HAMBRECHT R, WALTHER C, MOEBIUS-WINKLER S, GIELEN S, LINKE A, CONRADI K, ERBS S, KLUGE R, KENDZIORRA K, SABRI O, SICK P, SCHULER G: Percutaneous coronary angioplasty compared with exercise training in patients with stable coronary artery disease. A randomized trial. Circulation 109: 13711378, 2004.

HAMBRECHT R, WOLF A, GIELEN S, LINKE A, HOFER J, ERBS S, SCHOENE N, SCHULER G: Effects of exercise on coronary endothelial function in patients with coronary artery disease. $N$ Engl J Med 342: 454-460, 2000. 
HASKELL WL, ALDERMAN EL, FAIR JM, MARON DJ, MACKEY SF, SUPERKO R, WILLIAMS PT, JOHNSTONE IM, CHAMPAGNE MA, KRAUSS RM: Effects of intensive multiple risk factor reduction on coronary atherosclerosis and clinical cardiac events in men and women with coronary artery disease: the Stanford Coronary Risk Intervention Project (SCRIP). Circulation 89: 975-990, 1994.

JOLLY K, LIP GYH, TAYLOR RS, RAFTERY J, MANT J, LANE D, GREENFIELD S, STEVENS A: The Birmingham rehabilitation uptake maximisation study (BRUM): a randomised controlled trial comparing home-based with centre-based cardiac rehabilitation. Heart 95: 36-42, 2009.

KLECHA A, KAWECKA-JASZCZ K, BACIOR B, KUBINYI A, PASOWICZ M, KLIMECZEK P, BANYS R: Physical training in patients with chronic heart failure of ischemic origin: effect on exercise capacity and left ventricular remodeling. Eur J Cardiovasc Prev Rehabil 14: 85-91, 2007.

OLDRIDGE NB, GUYATT GH, FISCHER ME, RIMM AA: Cardiac rehabilitation after myocardial infarction: combined experience of randomized clinical trials. JAMA 260: 950-954, 1988.

PIEPOLI MF: Exercise training meta-analysis of trials in patients with chronic heart failure (ExTraMATCH). BMJ 328: 189-196, 2004.

REUSS CS, MORENO CA, APPLETON CP, LESTER SJ: Doppler tissue imaging during supine and upright exercise in healthy adults. J Am Soc Echocardiogr 18: 1343-1348, 2008.

SCHULER G, HAMBRECHT R, SCHLIERF G, GRUNZE M, METHFESSEL S, HAUER K, KUBLER W: Myocardial perfusion and regression of coronary artery disease in patients on a regimen of intensive exercise and low fat diet. J Am Coll Cardiol 19: 34-42, 1992.

SHEPHARD RJ, BALADY GJ: Exercise as cardiovascular therapy. Circulation 99: 963-972, 1999.

VANHEES L, STEVENS A, SCHEPERS D, DEFOOR J, RADEMAKERS F, FAGARD R: Determinants of the effects of physical training and of the complications requiring resuscitation during exercise in patients with cardiovascular disease. Eur J Cardiovasc Prev Rehabil 11: 304-312, 2004.

WEBB-PEPLOE KM, CHUA TP, HARRINGTON D, HENEIN MY, GIBSON DG, COATS AJS: Different response of patients with idiopatic and ischaemic dilated cardiomyopathy to exercise training. Int J Cardiol 74: 215-224, 2000.

ZBINDEN R, ZBINDEN S, MEIER P, HUTTER D, BILLINGER M, WAHL A, SCHMID JP, WINDECKER S, MEIER B, SEILER C: Coronary collateral flow in response to endurance exercise training. Eur J Cardiovasc Prev Rehabil 14: 250-257, 2007. 